\title{
Comparison of different adhesively-bonded joint types for mechanical structures
}

\author{
N. G. C. Barbosa' ${ }^{1}$ R. D. S. G. Campilho ${ }^{1,2^{*}}$, F. J. G. Silva ${ }^{1}$ and R. D. F. Moreira ${ }^{1}$
}

*Correspondence:
raulcampilho@gmail.com
${ }^{1}$ Departamento de
Engenharia Mecânica,
Instituto Superior de
Engenharia do Porto,
Instituto Politécnico
do Porto, Rua Dr. António
Bernardino de Almeida, 431,
$4200-072$ Porto, Portugal
Full list of author information
is available at the end of the
article

*Correspondence: raulcampilho@gmail.com Engenharia Mecânica, Instituto Superior de Engenharia do Porto, do Porto, Rua Dr. António Bernardino de Almeida, 431, Full list of author information article

\begin{abstract}
Adhesively-bonded joints are widely used to join structural components. The most common joint types are single-lap joints (SLJ), double-lap joints (DLJ), stepped-lap joints and scarf joints. Several factors influence the behaviour and strength of an adhesive joint, namely the type of adhesive (brittle or ductile, strong or weak) and joint geometry. One of the most important parameters that affects the joint strength is the overlap length $\left(L_{O}\right)$. A comparative study that involves several joint geometries and uses adhesives with different characteristics was carried out to check which type of adhesive is most suitable for a particular joint geometry. For this purpose, SLJ, DLJ, stepped-lap joints and scarf joints were chosen for testing with three adhesives. The experimental results were compared with numerical results obtained from Abaqus ${ }^{\circledR}$ using an integrated cohesive zone modelling module. Initially, a stress analysis was carried out to compare the different joint geometries. With this work, it was concluded that the optimal joint type significantly depends on the type of adhesive used, such that less strong and ductile adhesives are more suitable for joint geometries that exhibit large stress variations, while stronger but more brittle adhesives are recommended for joint geometries with more uniform stresses.
\end{abstract}

Keywords: Epoxy, Polyurethane, Finite element analysis, Fracture mechanics, Cohesive zone models

\section{Introduction}

Adhesive bonding has been widely used in several industries, such as automotive and aeronautical. Nowadays, and with the advances of adhesive science, the use of this type of joining method has become more appealing due to the higher peel and shear strengths and also allowable ductility up to failure of the adhesives [1,2]. Adhesivelybonded joints have some advantages over traditional joints (welded, bolted or riveted), such as reduced weight, more uniform stress distributions, absence of damage in the bonded parts, ease of manufacture and the possibility to join dissimilar materials [3]. However, bonded joints are yet not reliable in critical connections because of issues like fatigue and long-term behaviour uncertainties, and large scatter in the failure loads [4]. Two alternatives may be chosen for the analysis of adhesive joints: closed-loop analyses or analytical methods and numerical methods (e.g. finite element method or FEM). The first prediction methods for adhesive structures consisted of analytical formulations, 
and the work of Volkersen [5] and Goland and Reissner [6] were precursors of several theoretical studies. The main advantage is the simplicity in obtaining the stress distributions in the adhesive, due to the simplified assumptions in terms of structure geometry, load, and boundary conditions. The most popular technique for the strength prediction of adhesive joints is the FEM $[7,8]$. Initially, the continuous mechanics approach was considered, which required the stress distributions and an adequate failure criteria [9]. A FEM analysis can also be used in conjunction with fracture mechanics criteria for strength prediction, either by stress intensity factors or by an energy approach [10]. In the last decades new methodologies were introduced, one of which is modelling damage growth by combining the FEM with CZM [11]. This technique combines conventional FEM modelling for regions that are expected to be undamaged and a Fracture Mechanics approach for the cohesive elements to stimulate the crack growth [12]. A very recent alternative to the crack propagation model inside materials is the extended finite element method (XFEM), which uses enriched form functions to represent a discontinuous displacement field [13]. Few works apply this technique in bonded joints [14].

The most used joint types are SLJ, DLJ, stepped-lap joints and scarf joints. Undoubtedly, the SLJ is the most studied joint type due to the easy fabrication process, although the efficiency averaged to the bonded length is the worst between the mentioned joint types $[15,16]$. DLJ are also simple to fabricate but there is a need to have access to both sides of the structures to perform these joints. However, the efficiency of this joint is much higher than that of the SLJ because of duplicating the shear-resistant area for the same $L_{\mathrm{O}}$ [17]. Stepped-lap and scarf joints have an improved overall performance for the same bonded area, but the components to be bonded need milling operations, which makes the joints more demanding to fabricate $[18,19]$.

A large number of authors presented studies on different joint configurations, and some of these are purely experimental. The study of Papanicolaou et al. [20] focuses on an experimental and analytical investigation of unbalanced boron/epoxy-aluminium (2024-T3 alloy) SLJ subjected to a tensile loading, after being exposed to a corrosive environment, in order to study this effect on the maximum load $\left(P_{\mathrm{m}}\right)$ and failure mode. A high strength adhesive (FM94) was used for bonding and different $L_{\mathrm{O}}$ were tested. The results mainly prove that $L_{\mathrm{O}}$ and the aging conditions directly affect $P_{\mathrm{m}}$, and that an optimum value of $L_{\mathrm{O}}$ can be defined. The maximum through-thickness normal $\left(\sigma_{\mathrm{y}}\right)$ and shear stresses $\left(\tau_{x y}\right)$ increase with bigger $L_{\mathrm{O}}$, resulting in a non-proportional $P_{\mathrm{m}}$ improvement with $L_{\mathrm{O}}$. The experimental work of Lee et al. [21] reports on joint strengths, $\sigma_{\mathrm{y}}$ stresses (by extensometry) and failure modes in adhesively-bonded double-strap and supported glass-fibre reinforced polymer (GFRP) SLJ, bonded with three different epoxy adhesives. The load-displacement curves and $P_{\mathrm{m}}$ of the double-strap joints were compared with those of the supported SLJ to show the superior strength characteristics of the double-strap joints. It was shown that $P_{\mathrm{m}}$ was almost independent of the adhesive type, decreased with the adhesive layer thickness and increased with $L_{\mathrm{O}}$. It was also concluded that $P_{\mathrm{m}}$ of the double-strap joints is highly dependent on $L_{\mathrm{O}}$. Actually, an almost $50 \%$ increase in $P_{\mathrm{m}}$ was found by doubling $L_{\mathrm{O}}$ from 50 to $100 \mathrm{~mm}$.

Other works included numerical simulation, eventually supported by experiments for validation purposes. Nunes et al. [17] compared the tensile performance of SLJ and DLJ bonded with three different adhesives. The authors concluded that the joints' behaviour 
is highly dependent on the adhesive type. $P_{\mathrm{m}}$, either for SLJ or DLJ, was very limited with the increase of $L_{\mathrm{O}}$ for the adhesive Araldite ${ }^{\circledR}$ AV138, due to its brittle behaviour. For the Araldite ${ }^{\circledR} 2015$, which enables plasticization of the adhesive bond when the limiting stresses are attained, results showed an increased performance for higher $L_{\mathrm{O}}$. The Sikaforce ${ }^{\circledR} 7888$, which manages to combine high strength with ductility, showed a better performance for both small and large $L_{\mathrm{O}}$. Liao et al. [22] numerically studied the effects of the adhesive thickness $\left(t_{\mathrm{A}}\right)$, adhesive type and scarf angle $(\alpha)$, on the failure behaviour of adhesive scarf joints subjected to uniaxial tensile loading. A mixed-mode CZM with a bilinear shape coupled to a FEM subroutine was used to induce cohesive failure of the adhesive. The numerical results demonstrated that $P_{\mathrm{m}}$ increases with the reduction of $t_{\mathrm{A}}$. The authors concluded that the main parameters that evaluate the performances of SLJ, e.g. $P_{\mathrm{m}}$, maximum applied displacement and failure energy, increase with the reduction of $\alpha$. Regarding $P_{\mathrm{m}}$, the joint loses the load-bearing capacity when adopting the brittle adhesive, while it keeps partial load-bearing capacity with the ductile adhesive. The strength improvement of adhesively-bonded scarf repairs in aluminium structures with external reinforcements was investigated in Ref. [23], using two adhesives (a britthe and a moderately ductile). It was concluded that the repair strength increases with the decrease of $\alpha$ and also with the bonding of external reinforcements. The strength of the adhesively-bonded stepped-lap joints with different step numbers was analysed by Akpinar [24]. The tensile behaviour of SLJ, one-step lap joints and three-step lap joints was experimentally and numerically examined by keeping an identical bonding length between all samples examined. The samples for the three different joint types used in the experimental studies were modelled three dimensionally by using Ansys package software. Multilinear isotropic hardening-von Mises plasticity was considered as material model. Failure was assessed by using a simple continuum mechanics criterion based on the von-Mises stresses. The AA2024-T3 aluminium alloy was used for the adherends, while a flexible adhesive and a stiff adhesive were applied separately. The authors concluded that changing the joint geometry in the bonding region has a large impact on the stress concentrations arising in the adhesive joint and on the joints' load carrying capacity. According to the test data, the one-step and three-step lap joints bonded with the flexible adhesive suffered a strength improvement of $11 \%$ and $60 \%$, respectively, over the SLJ. Comparison of the load carrying capacities of joints bonded with the stiff adhesive shows that the one-step lap and three-step lap joints carried $8.8 \%$ and $68 \%$ more load than a conventional SLJ, respectively. The authors also concluded that the results of the experimental study and FEM are in close agreement. The results of the numerical analysis and experimental study show that critical loci for failure are the interface between adhesive layer and upper adherend. Ichikawa et al. [25] carried out a three-dimensional FEM stress analysis and strength evaluation of stepped-lap adhesive joints between mild steel adherends, subjected to static tensile loadings. The authors concluded the value of the maximum principal stress in the adhesive decreased with the increase of the adhesive Young's modulus, with the decrease of $t_{\mathrm{A}}$ and with the increase of the number of butted steps.

The main objectives of this work are to carry out a comparative study that involves several joint geometries and uses adhesives with different characteristics, to check which type of adhesive is most suitable for a particular joint geometry. For this purpose, SLJ, 


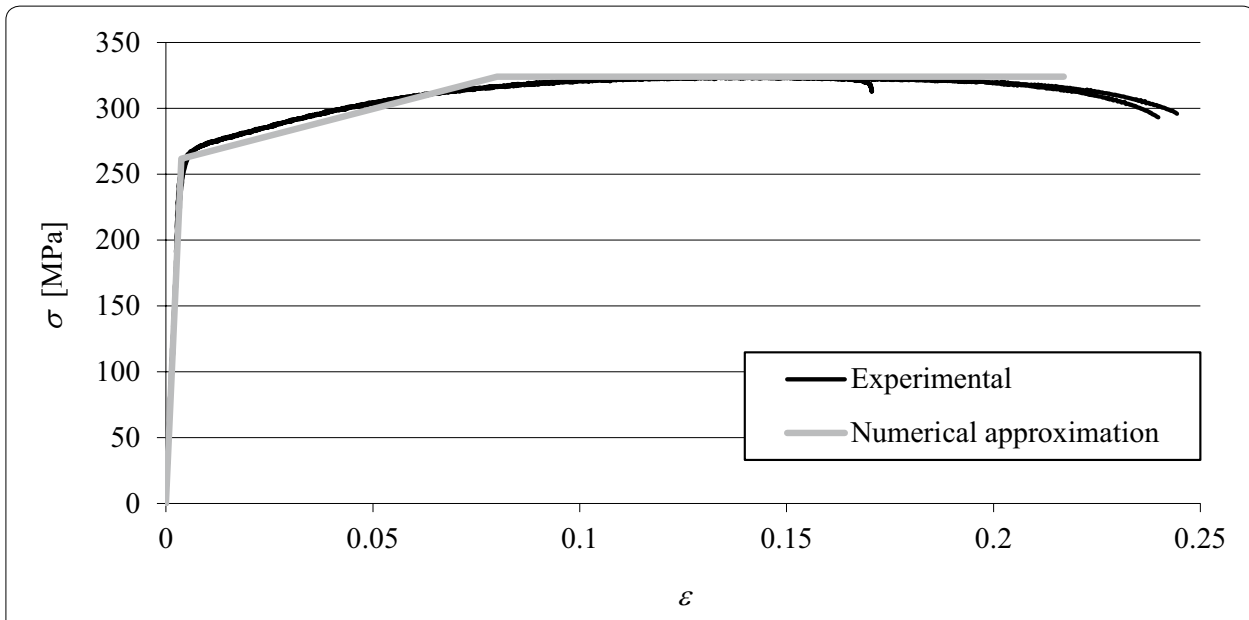

Fig. 1 Experimental and numerical $\sigma-\varepsilon$ curves of the aluminium

Table 1 Properties of the AW6082 T651 aluminium alloy [28]

\begin{tabular}{lr}
\hline Property & AW6082 T651 \\
\hline Young's modulus, $E(\mathrm{GPa})$ & $70.07 \pm 0.83$ \\
Yield stress, $\sigma_{\mathrm{y}}(\mathrm{MPa})$ & $261.67 \pm 7.65$ \\
Tensile strength, $\sigma_{\mathrm{f}}(\mathrm{MPa})$ & $324.00 \pm 0.16$ \\
Tensile failure strain, $\varepsilon_{\mathrm{f}}(\%)$ & $21.70 \pm 4.24$ \\
\hline
\end{tabular}

DLJ, stepped-lap joints and scarf joints were chosen for testing with three adhesives. The experimental results are compared with numerical results obtained using Abaqus ${ }^{\circledR}$ using an integrated CZM module. Initially, a stress analysis is carried out to compare the different joint geometries.

\section{Methods}

\section{Experimental work}

\section{Characterization of the joint materials}

For the adherends material, the choice was the aluminium alloy AW6082 T651, which is distinguished by an elevated tensile strength (340 MPa, manufacturer's specification). The material was supplied in $1 \mathrm{~m}$ long bars that had to be cut in specimens with the desired length, using a disc cutter. In conformity with the standard ASTM-E8M-04 [26], the stress-strain $(\sigma-\varepsilon)$ curves of the aluminium alloy as a bulk are shown in Fig. 1. The numerical simulations were carried out using the approximation of the adherend material shown in Fig. 1. The mechanical properties and values of standard deviation are presented in Table 1. The adhesives used in the experimental tests are the following: Sikaforce ${ }^{\circledR} 7752$ (ductile), Araldite ${ }^{\circledR} 2015$ (moderately ductile) and Araldite ${ }^{\circledR}$ AV138 (brittle). All these adhesives were tested in previous works concerning the most relevant mechanical and toughness properties [27-29]. In order to obtain the tensile mechanical properties $\left(E, \sigma_{\mathrm{y}}, \sigma_{\mathrm{f}}\right.$ and $\left.\varepsilon_{\mathrm{f}}\right)$ of the three adhesives, tests were conducted on bulk specimens. Figure 2 shows representative $\sigma-\varepsilon$ curves of the tensile tests conducted on the three adhesives. The equivalent shear properties were estimated from thick-adherend 


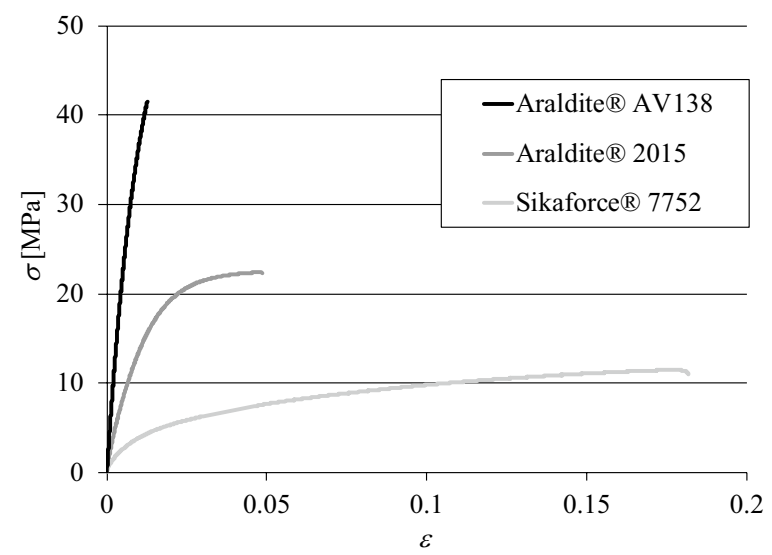

Fig. $2 \sigma-\varepsilon$ curves comparison of the adhesives Araldite ${ }^{\circledR}$ AV138, Araldite ${ }^{\circledR} 2015$ and Sikaforce ${ }^{\circledR} 7752$

Table 2 Properties of the adhesives Araldite ${ }^{\circledR}$ AV138, Araldite ${ }^{\circledR} 2015$ and Sikaforce ${ }^{\circledR} 7752$ [27-29]

\begin{tabular}{llll}
\hline Property & AV138 & $\mathbf{2 0 1 5}$ & $\mathbf{7 7 5 2}$ \\
\hline Young's modulus, $E(\mathrm{GPa})$ & $4.89 \pm 0.81$ & $1.85 \pm 0.21$ & $0.49 \pm 0.09$ \\
Poisson's ratio, $V$ & $0.35^{\mathrm{a}}$ & $0.33^{\mathrm{a}}$ & $0.30^{\mathrm{a}}$ \\
Tensile yield stress, $\sigma_{\mathrm{y}}(\mathrm{MPa})$ & $36.49 \pm 2.47$ & $12.63 \pm 0.61$ & $3.24 \pm 0.48$ \\
Tensile failure strength, $\sigma_{\mathrm{f}}(\mathrm{MPa})$ & $39.45 \pm 3.18$ & $21.63 \pm 1.61$ & $11.48 \pm 0.25$ \\
Tensile failure strain, $\varepsilon_{\mathrm{f}}(\%)$ & $1.21 \pm 0.10$ & $4.77 \pm 0.15$ & $19.18 \pm 1.40$ \\
Shear modulus, $G(\mathrm{GPa})$ & $1.81^{\mathrm{b}}$ & $0.70^{\mathrm{b}}$ & $0.19^{\mathrm{b}}$ \\
Shear yield stress, $\tau_{\mathrm{y}}(\mathrm{MPa})$ & $25.1 \pm 0.33$ & $14.6 \pm 1.3$ & $5.16 \pm 1.14$ \\
Shear failure strength, $\tau_{\mathrm{f}}(\mathrm{MPa})$ & $30.2 \pm 0.40$ & $17.9 \pm 1.8$ & $10.17 \pm 0.64$ \\
Shear failure strain, $\gamma_{\mathrm{f}}(\%)$ & $7.8 \pm 0.7$ & $43.9 \pm 3.4$ & $54.82 \pm 6.38$ \\
$\mathrm{G}_{\mathrm{IC}}(\mathrm{N} / \mathrm{mm})$ & $0.20^{\mathrm{c}}$ & $0.43 \pm 0.02$ & $2.36 \pm 0.17$ \\
$\mathrm{G}_{\mathrm{IIC}}(\mathrm{N} / \mathrm{mm})$ & $0.38^{\mathrm{c}}$ & $4.70 \pm 0.34$ & $5.41 \pm 0.47$ \\
\hline
\end{tabular}

a Manufacturer's data

b Estimated from the Hooke's law using $E$ and $v$

c Estimated in Campilho et al. [28]

shear tests (TAST) using steel adherends. On the other hand, to estimate the fracture properties, the following test methods were applied: double-cantilever beam (DCB) for the tensile toughness $\left(G_{\mathrm{IC}}\right)$ and end-notched flexure (ENF) for the shear toughness $\left(G_{\text {IIC }}\right)$. The obtained data is summarized in Table 2.

\section{Experimental details}

The geometry of the SLJ, DLJ, stepped-lap and scarf joints is depicted in Fig. 3. The relevant dimensional parameters are: adherends' thickness $t_{\mathrm{P}}=3 \mathrm{~mm}, t_{\mathrm{A}}=0.2 \mathrm{~mm}$, thickness of the vertical adhesive layers for the stepped-lap joints $t_{\mathrm{A} 1}=0.2 \mathrm{~mm}, L_{\mathrm{O}}=12.5,25$, 37.5 and $50 \mathrm{~mm}, \alpha=3.43,10,15,20,30$ and $45^{\circ}$, and total length of the joint between grips $L_{\mathrm{T}}=170 \mathrm{~mm}$. It should be mentioned that $\alpha=3.43^{\circ}$ corresponds to $L_{\mathrm{O}}=50 \mathrm{~mm}$, such that a direct comparison can be made between joint types. For all joint types, five specimens were fabricated, making a total of 90 test specimens. In this work, for the DLJ, it was considered that the inner adherend had the same $t_{\mathrm{p}}$ value of the outer 

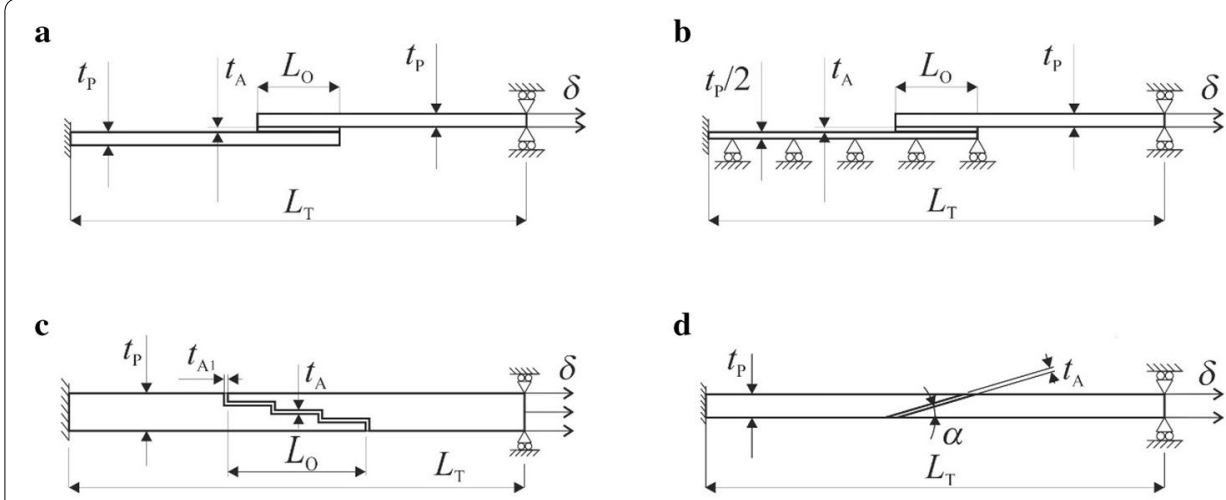

d

Fig. 3 Geometry and dimensions of the SLJ (a), DLJ (b), stepped-lap (c) and scarf joints (d)

adherends. It must be pointed out that this option does not compromise this study and its objectives. Regarding the manufacturing of the joints, the adherends were initially cut to their final block dimensions. Then, the final shape of the specimens for the scarf and stepped-lap joints was obtained by milling. Following, all adherends regardless the joint geometry were submitted to proper surface preparation to promote a strong bond that in the end will result in a cohesive failure. This operation consists of cleaning the specimens using grit blasting and then applying a degreaser. The SLJ, DLJ, stepped-lap and scarf joints were assembled to cure in a steel mould, to ensure a proper adherends' alignment and the correct value of $L_{\mathrm{O}}$. To obtain the specified $t_{\mathrm{A}}$, steel blocks with calibrated dimensions were used to support the upper adherend (SLJ) and inner and upper adherends (DLJ). The other joint types did not require this setup because the adherends are naturally aligned. For the scarf joints, clamps were used to position and align the adherends and, in order to obtain the specified $t_{\mathrm{A}}$, calibrated wire with $0.2 \mathrm{~mm}$ of diameter was applied between the adherends. For the SLJ, tabs were bonded at the joint ends, to obtain an adequate alignment in the testing machine. DLJ used a tab only between outer adherends. Due to their configuration, the other joints do not require this fabrication step. The time of cure for all joints was a minimum of $48 \mathrm{~h}$, at room temperature. To remove the excess adhesive at the overlap zone, milling techniques were applied. The tests were done, at room temperature, in a Shimadzu AG-X 100 testing machine, with a $100 \mathrm{kN}$ load cell and considering a grip velocity of $1 \mathrm{~mm} / \mathrm{min}$. Of the five specimens per joint type, a minimum of four valid results were provided. Figure 4 shows an example of a stepped-lap joint bonded with the Sikaforce ${ }^{\circledR} 7752$ and $L_{\mathrm{O}}=25 \mathrm{~mm}$ ready for testing (a) and a SLJ bonded with the Araldite ${ }^{\circledR} 2015$ and $L_{\mathrm{O}}=37.5 \mathrm{~mm}$ during a tensile test (b).

\section{Numerical modelling}

Model construction

For the four joint types, the numerical analyses were done in Abaqus ${ }^{\circledR}$. These analyses provided the strength prediction and stress distribution analysis. The analyses were performed considering geometrical non-linearities through all, to accurately model the significant joint rotations of the SLJ. For the strength analysis, the adherends were modelled as elasto-plastic continuum bodies and the adhesives were treated with cohesive elements. The two-dimensional joint models were mainly built with plane-strain 


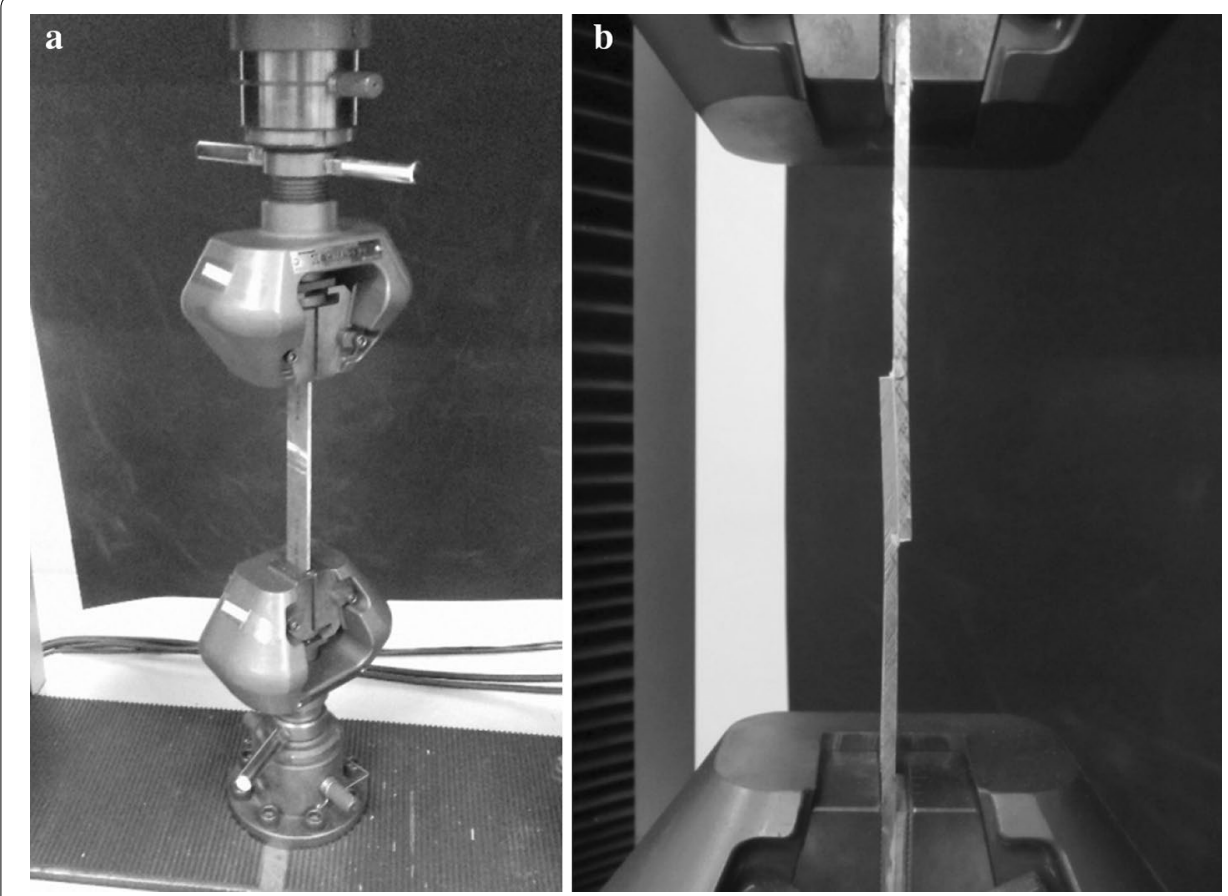

Fig. 4 Stepped-lap joint bonded with the Sikaforce ${ }^{\circledR} 7752$ and $L_{O}=25 \mathrm{~mm}$ ready for testing (a) and SLJ bonded with the Araldite 2015 and $L_{O}=37.5 \mathrm{~mm}$ during a tensile test (b)

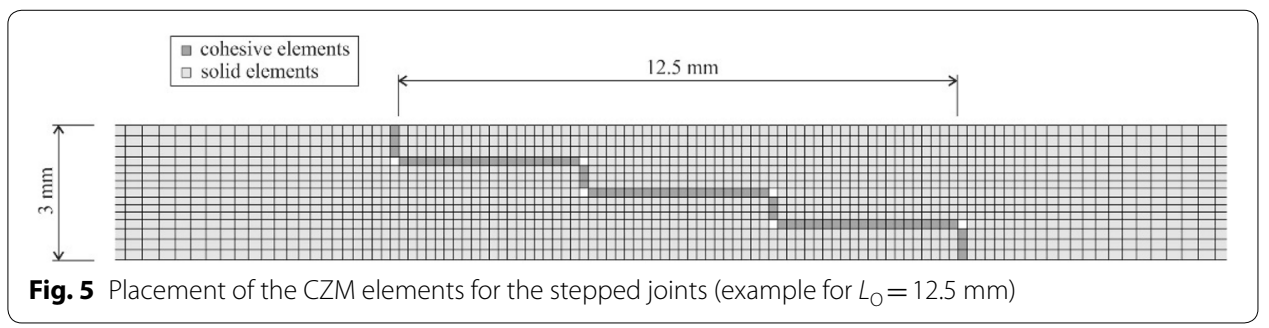

quadrilateral elements (CPE4) for the adherends. In the particular case of the scarf joints, plane-strain triangular elements (CPE3) were applied to model the tapered bonded edges. Regarding the bondline, a single layer of cohesive elements (COH2D4) was considered in the thickness direction, which follow a triangular traction-separation law. In the particular case of the stepped-lap joints, the adhesive was broken into horizontal and vertical segments, as shown in Fig. 5 (example for $L_{\mathrm{O}}=12.5 \mathrm{~mm}$ ). The discontinuity between these segments was applied because of the physical impossibility to model the corners between adhesive segments by CZM, and it is not expected to compromise the results' accuracy, because the loads that would be transferred through the corners is negligible. Figure 5 also shows the mesh applied to this joint. In the case of the DLJ, symmetry along the horizontal symmetry axis of the joint was applied. Figure 6 presents the mesh details for a $L_{\mathrm{O}}=25 \mathrm{~mm}$ DLJ (a) and a scarf joint with $\alpha=10^{\circ}$ (b). In the DLJ, emphasis is given on the symmetry conditions. For the stress analysis models, the aforementioned plane-strain quadrilateral elements (CPE4) were also applied in the adhesive layer, and stresses were extracted at the mid-thickness. Moreover, a more 

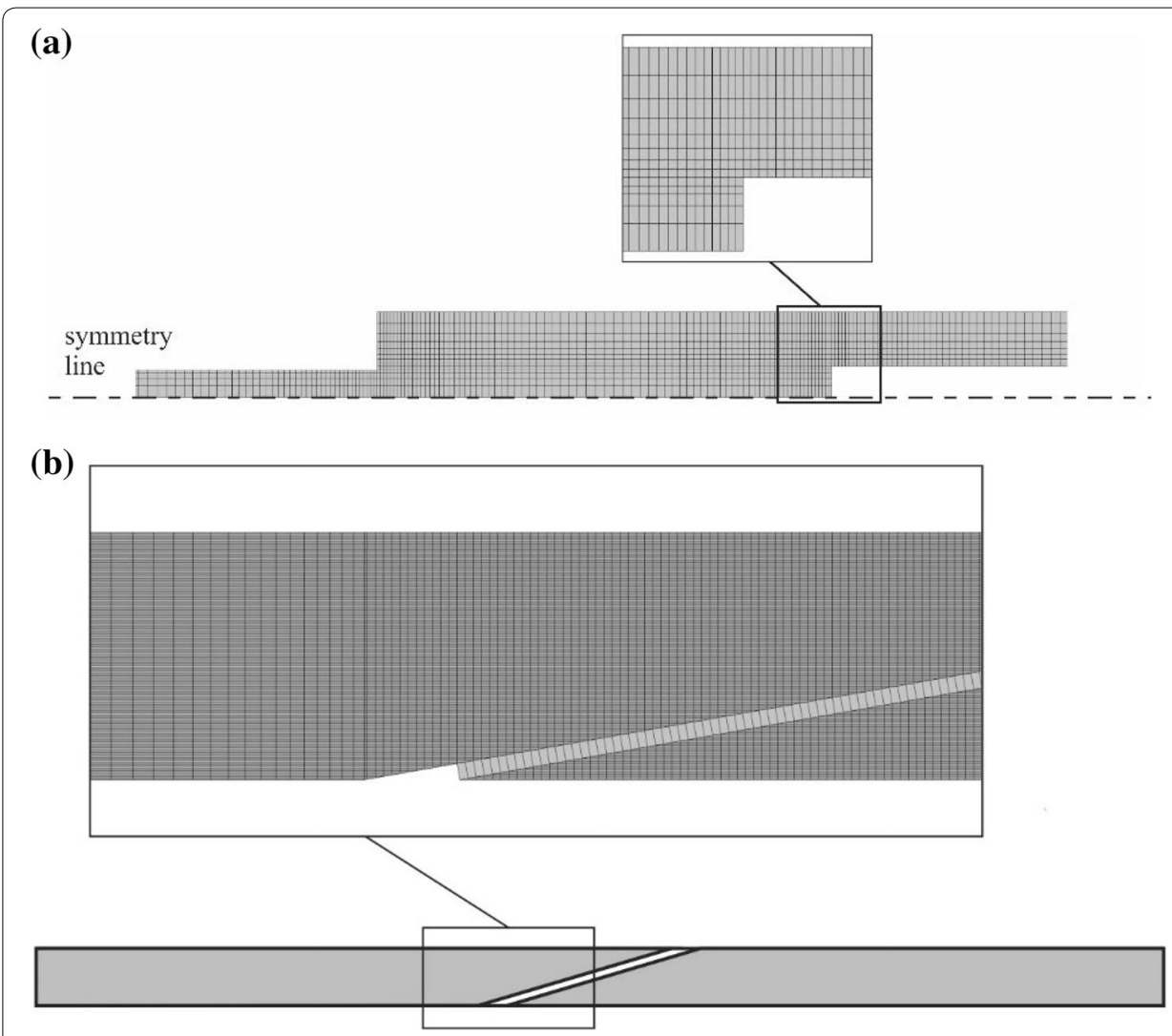

Fig. 6 Mesh detail for the $L_{O}=25 \mathrm{~mm} \mathrm{DLJ} \mathrm{(a)} \mathrm{and} \mathrm{for} \mathrm{the} \mathrm{scarf} \mathrm{joint} \mathrm{with} a=10^{\circ}$ (b)

refined mesh than the one used for the damage models analysis was considered, in order to obtain more precise results, mainly in the adhesive layer. With this purpose, ten solid elements were used for the adhesive layer in the thickness direction. The number of elements and bias ratio (i.e. mesh grading effects) largely depend on the need to obtain accurate stress estimations. Thus, the overlap zone had higher mesh refinement with a tendency to reduce towards the edges of the joint, not to affect the accuracy of the strength predictions. This approach is a common procedure in bonded joints' analysis [30] and it was done in order to reduce the required computational cost. To realistically simulate the experimental tests, boundary conditions were defined in a way that one of the joint edges was clamped and the other was subjected to a vertical restriction and a traction displacement.

\section{CZM formulation}

CZM are based on relationships between stresses and relative displacements connecting homologous nodes of the cohesive elements, usually addressed as CZM laws. These laws simulate the elastic behaviour up to a peak load and subsequent softening, to model the gradual degradation of material properties up to complete failure. The areas under the traction-separation laws in each mode of loading (tension and shear) are equalled to the respective value of fracture toughness $\left(G_{C}\right)$. Under pure mode, damage propagation occurs at a specific integration point when the stresses 


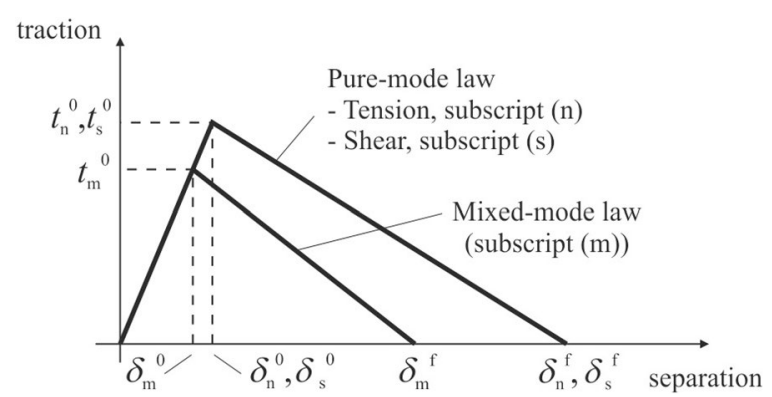

Fig. 7 Traction-separation law with linear softening law available in Abaqus ${ }^{\circledR}$

Table 3 CZM parameters of the three adhesives

\begin{tabular}{lccr}
\hline Property & AV138 & $\mathbf{2 0 1 5}$ & $\mathbf{7 7 5 2}$ \\
\hline$E(\mathrm{GPa})$ & 4.89 & 1.85 & 0.49 \\
$\mathrm{G}(\mathrm{GPa})$ & 1.81 & 0.70 & 0.19 \\
$t_{\mathrm{n}}^{0}(\mathrm{MPa})$ & 39.45 & 21.63 & 11.48 \\
$t_{\mathrm{s}}^{0}(\mathrm{MPa})$ & 30.2 & 17.9 & 10.17 \\
$\mathrm{G}_{\mathrm{IC}}(\mathrm{N} / \mathrm{mm})$ & 0.20 & 0.43 & 2.36 \\
$\mathrm{G}_{\| C}(\mathrm{~N} / \mathrm{mm})$ & 0.38 & 4.70 & 5.41 \\
\hline
\end{tabular}

are released in the respective traction-separation law. Under mixed mode, energetic criteria are often used to combine tension and shear [31]. In this work, triangular pure and mixed-mode laws, i.e. with linear softening, were considered for the analysis (Fig. 7). Although ductile adhesives such as the Sikaforce ${ }^{\circledR} 7752$ may be best modelled with CZM laws that reproduce the plastic behaviour more accurately, such as the trapezoidal law, here the triangular shape was considered to assess the capability of a simpler and readily available law in modelling such joints. The elastic behaviour of the cohesive elements up to the tipping tractions is defined by an elastic constitutive matrix relating stresses and strains across the interface, containing $E$ and the shear modulus $\left(G_{\mathrm{xy}}\right)$ as main parameters. Damage initiation under mixed-mode can be specified by different criteria. In this work, the quadratic nominal stress criterion was considered for the initiation of damage. After the cohesive strength in mixedmode $\left(t_{\mathrm{m}}^{0}\right)$ is attained, the material stiffness is degraded. Complete separation is predicted by a linear power law form of the required energies for failure in the pure modes. For full details of the presented model, the reader can refer to Ref. [32]. The properties of the adhesives for the simulations are given in Table 3 (estimated from the data of Table 2).

\section{Results and discussion}

This Section initially presents a description of the failure modes. A numerical stress distribution analysis in the adhesive layer is then undertaken, which assists in the following discussion regarding the experimental and numerical strength analysis, for a detailed understanding of the joints' behaviour. 


\section{Failure modes}

The majority of failures for all joint types occurred cohesively in the adhesive layer (Fig. 8), with some exceptions. For all the joints bonded with the Araldite ${ }^{\circledR}$ AV138 the type of failure was cohesive, although some of these cohesive failures took place near the interface. For the joints bonded with the Araldite ${ }^{\circledR} 2015$, the typical failure mode is also cohesive in the adhesive layer. However, failure for the stepped-lap joints and DLJ with $L_{\mathrm{O}}=50 \mathrm{~mm}$ was in the adherends by plasticization, due to the higher loads caused by the ductility of the adhesive. The joints bonded with the Sikaforce ${ }^{\circledR}$ 7752 suffered from cohesive failure of the adhesive, and adherends' plasticization was detected only for the DLJ with $L_{\mathrm{O}}=50 \mathrm{~mm}$. These failure modes are consistent with the numerical simulations performed further in this work.

\section{Peel and shear stresses comparison}

This Section compares $\sigma_{\mathrm{y}}$ and $\tau_{\mathrm{xy}}$ stress distributions for the SLJ, DLJ, stepped-lap and scarf joints at the adhesive mid-thickness and for $L_{\mathrm{O}}=12.5 \mathrm{~mm}$ and $50 \mathrm{~mm}$, such that a detailed discussion of the joint strengths can be introduced later in this work. It should be mentioned that the $L_{\mathrm{O}}=12.5 \mathrm{~mm}$ curve for the scarf joint was taken for $\alpha=15^{\circ}$, which corresponds to $L_{\mathrm{O}} \approx 11.2 \mathrm{~mm}$. All stress plots are normalized by $\tau_{\text {avg }}$, representing the average value of $\tau_{x y}$ in the adhesive bond for respective value of $L_{\mathrm{O}}$. These stresses were taken during the elastic part of the loading (adhesive and adherends) and are valid up to the onset of adhesive or adherend plasticization. The stress distributions relate to the Araldite ${ }^{\circledR} 2015$, although they can also represent the behaviour of the other adhesives in which regards a qualitative comparison between joint types and geometries (different $L_{\mathrm{O}}$ and $\alpha$ ). In fact, stress distributions are similar between adhesives, although small quantitative variations in $\sigma_{\mathrm{y}}$ and $\tau_{\mathrm{xy}}$ peak stresses were found depending on the adhesives' stiffness. This effect was tested in the work of

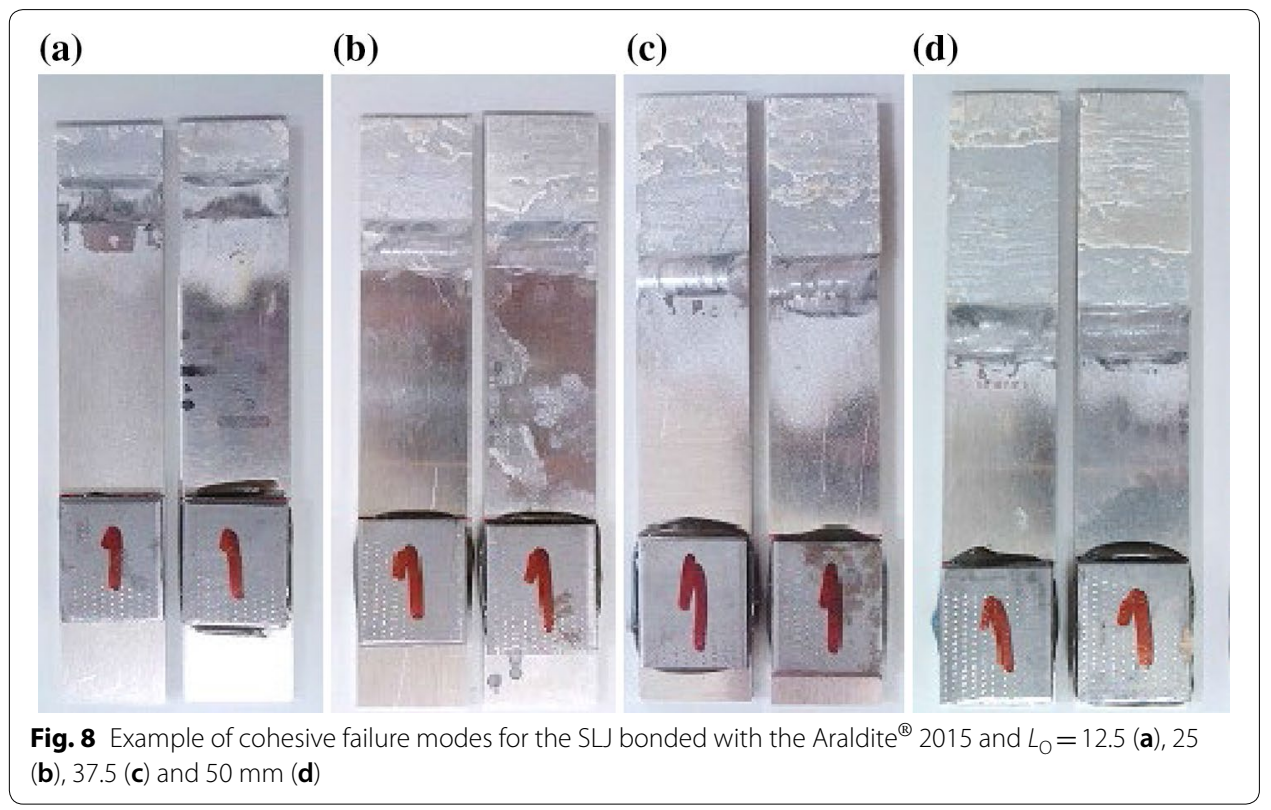


Ribeiro and Tita [33]. Thus, this study enables a perception of the stress modifications induced by changing either the joint type and geometry and to discuss the $P_{\mathrm{m}}$ tendencies found.

Figure 9 shows $\sigma_{\mathrm{y}}$ stress distributions for all the joint types and $L_{\mathrm{O}}=12.5$ (a) and $50 \mathrm{~mm}$ (b). The $y$-axis in Fig. 9b is truncated to provide an easier visualization. Between the different joints with $L_{\mathrm{O}}=12.5 \mathrm{~mm}$, the SLJ has the highest peak stress values between all joint types, of $\approx 3.2$ times the value of $\tau_{\mathrm{avg}}$, found at the overlap edges. This behaviour is due to the load asymmetry, leading to significant joint rotations and corresponding $\sigma_{\mathrm{y}}$ peak stresses at the mentioned locations [34]. This effect is minored in DLJ due to the load symmetry, which practically eliminates the transverse deflections and reflects on smaller $\sigma_{\mathrm{y}}$ peak stresses (up to 1.7 times $\tau_{\text {avg }}$ ), which still take place due to bending of the outer adherends [1,33]. Stepped-lap joints also result in an improved behaviour (highest $\sigma_{\mathrm{y}}$ peak stresses of 0.8 times $\tau_{\text {avg }}$ ), in this case owing to the adherends' collinearity, although variations between steps were still found [35]. The scarf joint provides the smoothest $\sigma_{\mathrm{y}}$ stress distribution along the bond length, although minor $\sigma_{\mathrm{y}}$ peak stresses are found at the overlap edges (up to 0.9 times $\tau_{\text {avg }}$ ), which is due to the highly advantageous tapering effect of the adherends and corresponding adherend stiffness reduction at the scarf tips [23]. Increasing $L_{\mathrm{O}}$ is usually linked to a degradation of stress distributions, in which concerns the increase of stress gradients (Fig. 9b). This is what happens for instance with the SLJ for $L_{\mathrm{O}}=50 \mathrm{~mm}$, with a maximum $\sigma_{\mathrm{y}} / \tau_{\mathrm{avg}}$ of 8.6, and it can be justified by the increasing bending moment and joint rotation effects with higher $L_{\mathrm{O}}$. The peak $\sigma_{\mathrm{y}} / \tau_{\text {avg }}$ for the DLJ also increases, from the aforementioned 1.7 to 5.5. Identically, this effect is also visible for the stepped-lap joint, with $\sigma_{\mathrm{y}} / \tau_{\text {avg }}$ attaining 2.3. The tendency is however different for the scarf joint, since in this case an increase of $L_{\mathrm{O}}$ is achieved by a reduction of $\alpha$. As a result, the $\sigma_{\mathrm{y}}$ component diminishes due to the adhesive layer becoming more and more aligned with the applied load [23]. In Fig. 9b, normalized $\sigma_{\mathrm{y}}$ stresses along the entire bondline are negligible, apart from highly concentrated peaks with $\sigma_{\mathrm{y}} / \tau_{\text {avg }}=0.7$.

Figure 10 depicts $\tau_{\text {xy }}$ stress plots for the same types of joints and limit $L_{\mathrm{O}}$ values: 12.5 (a) and $50 \mathrm{~mm}$ (b). Once again, for $L_{\mathrm{O}}=50 \mathrm{~mm}$, the $y$-axis was shortened for a clearer comparison. The comparative analysis shows an identical pattern to $\sigma_{\mathrm{y}}$ stresses between joint types, although with different grounds. Actually, initially considering $L_{\mathrm{O}}=12.5 \mathrm{~mm}$ (Fig. 10a), the SLJ plot deviates the most from $\tau_{\text {avg }}$, reaching a maximum of $\tau_{\mathrm{xy}} / \tau_{\text {avg }}$ of 2.2.

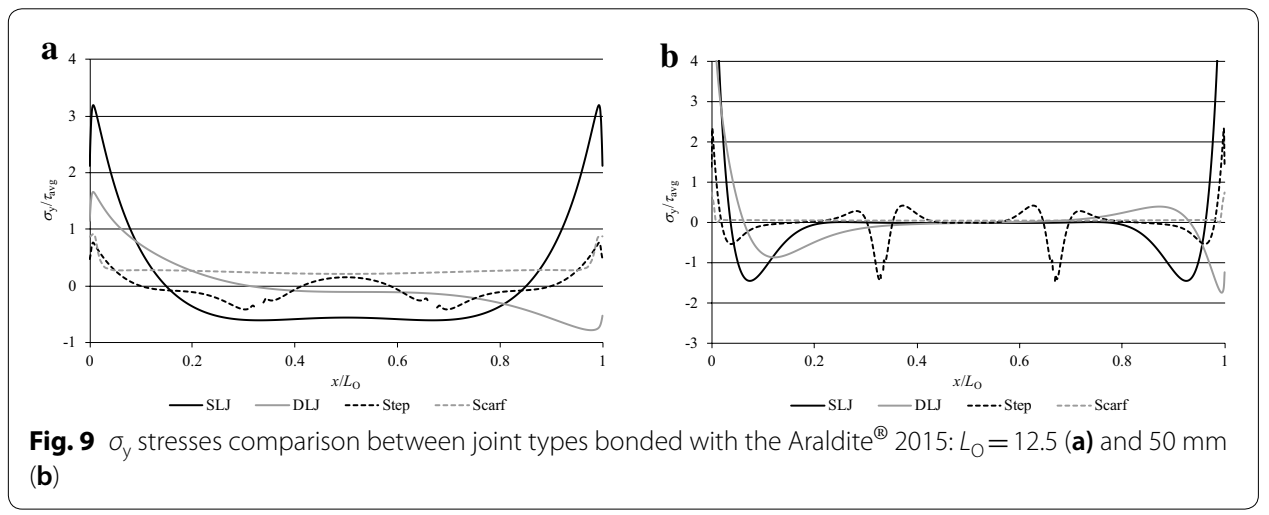



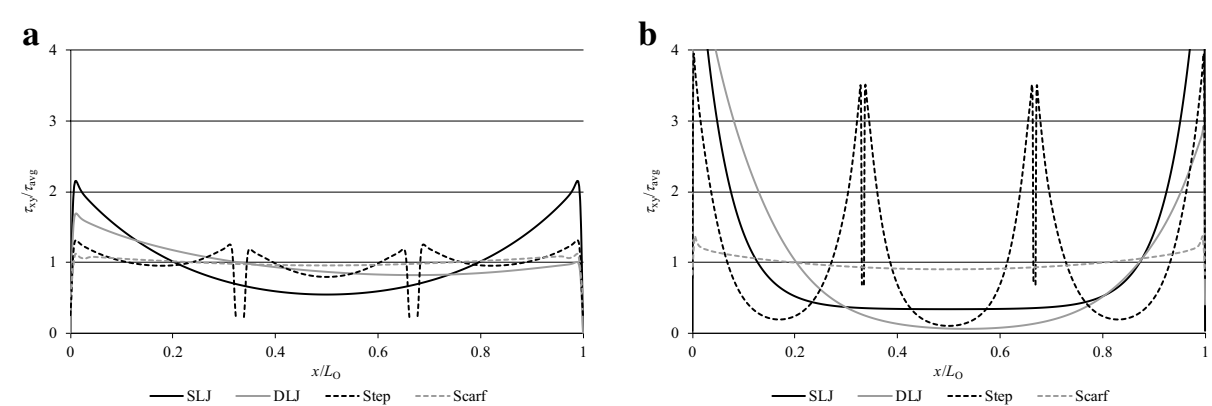

Fig. $10 \tau_{x y}$ stresses comparison between joint types bonded with the Araldite ${ }^{\circledR} 2015: L_{O}=12.5$ (a) and $50 \mathrm{~mm}(\mathbf{b})$

However, in this case, it is justified from the significant shear-lag of differential deformation effect of the adherends [34]. This concept originates from the increasing tensile straining of the two adherends along the overlap, from their free edge to the opposite edge, which results in $\tau_{x y}$ peak stresses at the overlap ends. $\tau_{x y}$ stress distributions for the DLJ, although more uniform than the SLJ, present a higher magnitude at the outer adherends' edge $\left(x / L_{\mathrm{O}}=0\right)$ end due to the higher loads induced to the middle adherend [36]. In this case, a maximum $\tau_{\text {xy }} / \tau_{\text {avg }}$ of 1.7 is found. The marked $\tau_{\text {xy }}$ peak stresses reduction at $x / L_{\mathrm{O}}=1$, compared to the SLJ, are due to smaller longitudinal deformation variations between the exterior and interior adherends. The behaviour of the stepped-lap joints is much improved over DLJ and especially SLJ, with the maximum $\tau_{\mathrm{xy}} / \tau_{\text {avg }}$ ratio peaking at 1.3. In fact, the stepped-lap joint, owing to its step-wise construction and thickness reduction towards the adherends ends at the overlap, is able to divide the load in a much more efficient manner between the steps [35]. However, the scarf joint clearly outperforms all the other joints, with a lowest $\tau_{\text {xy }} / \tau_{\text {avg }}=1.1$, due to the continuous and linear cross-section reduction in the bonded area, arising from the linear tapering of the adherends, which reflects on the almost absence of shear-lag effect [23]. The increase of $L_{\mathrm{O}}$ causes a major disruption on $\tau_{\mathrm{xy}}$ stresses for all joints except scarf, equally to what was discussed for $\sigma_{\mathrm{y}}$ stresses. At $L_{\mathrm{O}}=50 \mathrm{~mm}$ (Fig. $10 \mathrm{~b}$ ), $\tau_{\mathrm{xy}} / \tau_{\text {avg }}$ reaches a maximum of 6.4 for the SLJ, due to the increased amount of differential deformation of the two adherends at the overlap [17]. The DLJ follows the same path, by increasing this ratio from $1.7\left(L_{\mathrm{O}}=12.5 \mathrm{~mm}\right)$ to $6.0\left(L_{\mathrm{O}}=50 \mathrm{~mm}\right)$. The perceived difference between Fig. 10a, b regarding the stepped-lap joint is significant, and in this case a maximum $\tau_{\text {xy }} / \tau_{\text {avg }}$ of 3.9 takes place for $L_{\mathrm{O}}=50 \mathrm{~mm}$. The scarf joint is scarcely affected by the modification of $L_{\mathrm{O}}$ due to its improved geometry [23] and $\tau_{\text {xy }} / \tau_{\text {avg }}$ increases just to 1.4 .

Thus, this discussion makes clear that the scarf joint should perform best for the same bonded area of adhesive, followed by the stepped-lap joint. The DLJ only outperforms the SLJ, which clearly gives the worst performance, but it should be considered that, for the same $L_{\mathrm{O}}$, the DLJ has twice the bonded area than all other joints. As a result, these differences should result in a distinct joint behaviour, although the joints' performance also depends on the adhesive type, in the sense that, typically, more brittle adhesives are more sensitive to peak stresses. Moreover, at high transmitted loads, which typically take place for higher $L_{\mathrm{O}}$, another issue has importance: plasticization of the adherends. All these issues will be discussed further in the strength analysis that will follow. 


\section{Experimental joint strength}

This Section begins by making a comparative analysis of the three adhesives, as a function of the joint geometry. Figure 11a compares $P_{\mathrm{m}}$ for the different joint types bonded with the Araldite ${ }^{\circledR}$ AV138. This adhesive achieves the best result for the scarf joint with $L_{\mathrm{O}}=50 \mathrm{~mm}\left(\alpha=3.43^{\circ}\right)$. This adhesive is very stiff and brittle. The high peak stresses that usually exist in adhesives with high stiffness typically lead to premature failures and reduce the joints' performance. However, in scarf joints, stresses are almost uniform (Figs. 9, 10) [23], which makes a strong but brittle adhesive behaviour to behave well, oppositely to what happens with SLJ. Since stresses remain practically uniform even with large bond areas, scarf joints with large $L_{\mathrm{O}}$ (small $\alpha$ ) are particularly suited for this adhesive. However, for smaller $L_{\mathrm{O}}$ values, DLJ behave much better than all other joint types, including scarf, because DLJ have two layers of adhesive, which duplicates the adhesive area for the same $L_{\mathrm{O}}$. Thus, for short $L_{\mathrm{O}}$, which promote stresses with not too marked variations (Figs. 9, 10), this joint type shows a good compromise. However, bigger $L_{\mathrm{O}}$ quickly lead to high peak stresses (Figs. 9, 10), with the corresponding lack of advantage for brittle adhesives [37]. The SLJ and steppedlap joint obtain the worst results, mainly for the bigger values of $L_{\mathrm{O}}$, because the high brittleness of the Araldite ${ }^{\circledR}$ AV138 prevents any plasticization effect before failure of the adhesive, thus leading to premature failure. On the other hand, this plasticization already occurs in adhesives such as the Araldite ${ }^{\circledR} 2015$ and Sikaforce ${ }^{\circledR} 7752$, which are ductile adhesives, enabling them to reach higher $P_{\mathrm{m}}$ values for the same joint geometries. In conclusion, for bigger $L_{\mathrm{O}}$, the scarf joint is recommended. However, for short $L_{\mathrm{O}}$, DLJ have a slight advantage. The SLJ and stepped-lap joints are closer to the optimal $P_{\mathrm{m}}$ for short $L_{\mathrm{O}}$, while for higher $L_{\mathrm{O}}$ they become inadequate.

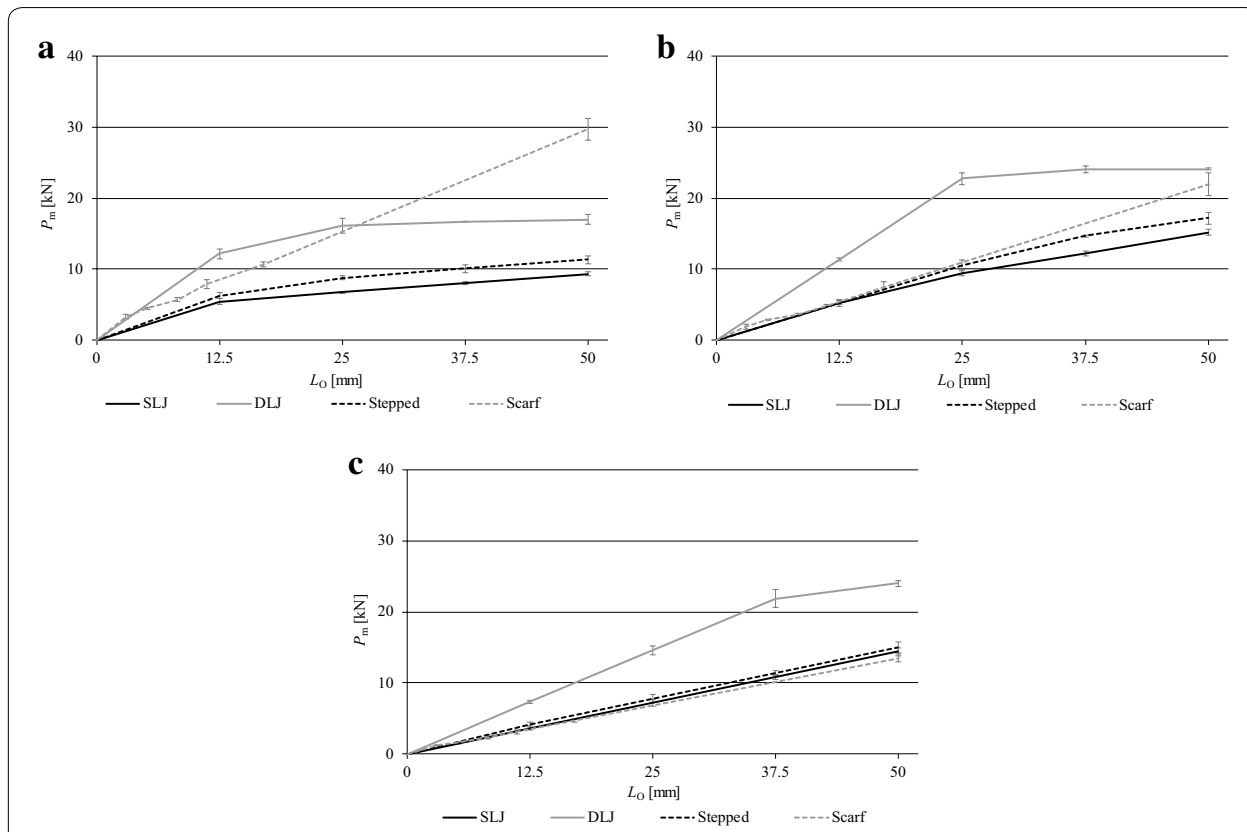

Fig. 11 Experimental $P_{m}$ as a function of $L_{0}$ for the different joint types bonded with the Araldite ${ }^{\circledR} \operatorname{AV} 138$ (a), Araldite ${ }^{\circledR} 2015$ (b) and Sikaforce ${ }^{\circledR} 7752$ (c) 
Figure $11 \mathrm{~b}$ presents the experimental $P_{\mathrm{m}}$ results for all joints bonded with the Araldite ${ }^{\circledR}$ 2015. For this adhesive, the DLJ performs best, irrespectively of $L_{\mathrm{O}}$. This difference to the previous adhesive is due to the plasticization capacity of this adhesive, which makes the double bonding area of the DLJ preponderant, despite the existing peak stresses (Figs. 9, 10) [17]. Despite this fact, it is possible to verify that, for $L_{\mathrm{O}}>25 \mathrm{~mm}, P_{\mathrm{m}}$ is little affected by the increase of $L_{\mathrm{O}}$, once the adherends' yield limit is reached. Due to its improved stress distributions (Figs. 9, 10) [38], the scarf joints show a nearly proportional increase of $P_{\mathrm{m}}$ with $L_{\mathrm{O}}$. For $L_{\mathrm{O}}=50 \mathrm{~mm}\left(\alpha=3.43^{\circ}\right)$, it approaches $P_{\mathrm{m}}$ of the DLJ. However, further $L_{\mathrm{O}}$ increase (or, correspondingly, $\alpha$ reduction) would trigger adherends' yielding with small benefit to the joint strength. The SLJ and stepped-lap joint attained very similar values to the scarf joint up to $L_{\mathrm{O}}=25 \mathrm{~mm}$ because, under these conditions, peak stresses are limited (Figs. 9 and 10) [25, 39] and the adhesive still has some peak stress absorption capacity. However, above this $L_{\mathrm{O}}$ these joints show increasing differences to the scarf joint (especially the SLJ), because of the corresponding degradation of stress distributions The SLJ and the stepped-lap joint obtained identical $P_{\mathrm{m}}$ values up to $L_{\mathrm{O}}=25 \mathrm{~mm}$ but, above this value, the stepped-lap joint clearly outperforms the SLJ. This difference is based on the moderate ductility of this adhesive, which allows to absorb the smaller peak stresses of the SLJ up to $L_{\mathrm{O}}=25 \mathrm{~mm}$, but fails to do so for higher $L_{\mathrm{O}}$ because of the higher peak stresses, which reflects in the cancel of the proportionality between $P_{\mathrm{m}}$ and $L_{\mathrm{O}}$. On the other hand, due to the more uniform stress distributions of the stepped-lap joints (Figs. 9, 10) [25], higher strengths are attained for the bigger $L_{\mathrm{O}}$. To conclude, for the Araldite ${ }^{\circledR} 2015$, the DLJ always provide the best results since, due to this adhesive's ductility, the bonded area is preponderant over peak stresses of the different joint types. The difference is highest for short $L_{\mathrm{O}}$, while for higher $L_{\mathrm{O}}$ the scarf joint approaches the DLJ.

Figure 11c compares $P_{\mathrm{m}}$ for the different joint types with the Sikaforce ${ }^{\circledR} 7752$. For this adhesive, the DLJ outperforms all other joint types by a significant amount. For this joint type, up to $L_{\mathrm{O}}=37.5 \mathrm{~mm}$, the increase of $P_{\mathrm{m}}$ with $L_{\mathrm{O}}$ is proportional. Above this value, the adherends' plasticization limits the joint strength and the proportionality is cancelled. Since $L_{\mathrm{O}}=50 \mathrm{~mm}$ nearly reaches the failure strength of the aluminium adherends, no further $L_{\mathrm{O}}$ increase is recommended with this adhesive. The other joint types showed identical results between them, with maximum $P_{\mathrm{m}}$ of $\approx 15 \mathrm{kN}$ compared to $P_{\mathrm{m}} \approx 24 \mathrm{kN}$ for the DLJ. The identical behaviour between the SLJ, stepped-lap joints and scarf joints is caused by the extreme ductility of this adhesive, which manages to absorb practically all peak stresses. Under these conditions the scarf joint, which has the most convenient stress distributions (Figs. 9, 10) [40], excels only by a slight difference the SLJ and stepped-lap joint. However, between these three joint types, the SLJ may be recommended because of the fabrication ease. The scarf and stepped-lap joint may be a good solution if a flush joining surface is required.

\section{Numerical joint strength}

This Section regards the comparison between the CZM $P_{\mathrm{m}}$ estimates with the average experimental results for validation purposes, and also to provide a more detailed comparison between joint types. The results are presented by joint type rather than by adhesive, to facilitate the analysis and to give a different view to the subject, comparing to the 
previous Section. Figure 12a compares the $P_{\mathrm{m}}$ results for the SLJ, considering the three adhesives. For the Araldite ${ }^{\circledR}$ AV138, the numerical $P_{\mathrm{m}}$ values are in good agreement with the experimental values, and are generally within the experimental scatter, except for $L_{\mathrm{O}}=25 \mathrm{~mm}$, in which the numerical prediction is approximately $60 \mathrm{~N}$ offset from the experimental scatter limit. The maximum deviation was $4.3 \%$ for $L_{\mathrm{O}}=12.5 \mathrm{~mm}$ (but still within the experimental scatter). The numerical $P_{\mathrm{m}}$ for the SLJ bonded with the Araldite ${ }^{\circledR}$ 2015 are within the experimental range for $L_{\mathrm{O}}=12.5$ and $25 \mathrm{~mm}$ but, for bigger $L_{\mathrm{O}}$, the experimental values fall short of the numerical prediction (up to $5.9 \%$ for $L_{\mathrm{O}}=50 \mathrm{~mm}$ ). This small deviation is probably due to the fact that these geometries undergo plasticity, which brings additionally modelling difficulties. The behaviour is different for the SLJ with the Sikaforce ${ }^{\circledR} 7752$, since here the mismatch begins at the smallest $L_{\mathrm{O}}(12.5 \mathrm{~mm})$, with a non-negligible CZM under prediction, which extends to all $L_{\mathrm{O}}$ tested (maximum of $16.0 \%$ for $L_{\mathrm{O}}=50 \mathrm{~mm}$ ). This discrepancy between the numerical and experimental $P_{\mathrm{m}}$ is caused by the large ductility of the adhesive and lack of capacity of the triangular CZM model to reproduce this behaviour. Under these conditions, a trapezoidal law would give better results [41]. Between adhesives, for the SLJ the Araldite ${ }^{\circledR} 2015$ is the adhesive that performs best for all $L_{\mathrm{O}}$ although, for $L_{\mathrm{O}}=12.5 \mathrm{~mm}, P_{\mathrm{m}}$ is identical to that of the Araldite ${ }^{\circledR}$ AV138. The Sikaforce ${ }^{\circledR} 7752$ surpasses the Araldite ${ }^{\circledR}$ AV138 for $L_{\mathrm{O}} \geq 37.5 \mathrm{~mm}$.

The DLJ results are presented in Fig. 12b for the three tested adhesives. The behaviour for the joints bonded with the Araldite ${ }^{\circledR}$ AV138 is similar to that of the SLJ, and almost a perfect match was attained between the CZM and experimental results (maximum deviation of $5.4 \%$ for $L_{\mathrm{O}}=12.5 \mathrm{~mm}$ ). This level of agreement is mainly due to this adhesive's brittleness, which is accurately modelled by a triangular CZM. The $P_{\mathrm{m}}$ predictions were also in agreement with the experimental values for the Araldite 2015 but, in this case, the adherends' failure governed $P_{\mathrm{m}}$ for $L_{\mathrm{O}} \geq 25 \mathrm{~mm}$.

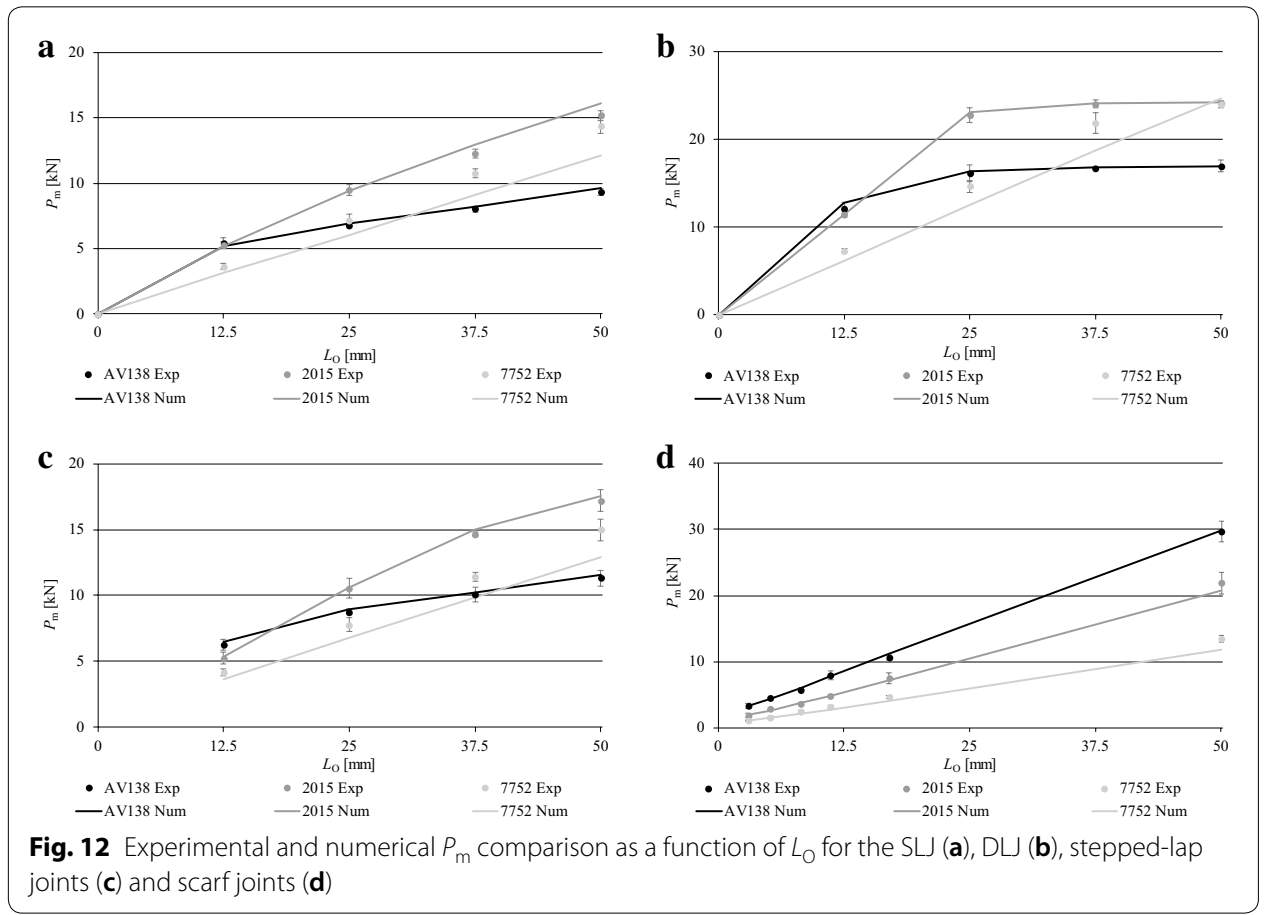


Thus, in these simulations, there are the adherends' properties rather than those of the adhesive that dictate the outcome of the simulation. The maximum percentile deviation for this adhesive was $1.9 \%$, for $L_{\mathrm{O}}=25 \mathrm{~mm}$. The numerical results for the Sikaforce ${ }^{\circledR} 7752$ reveal some deviation, equally to what happened for the SLJ, due to identical reasons (maximum deviation of $15.6 \%$ for $L_{\mathrm{O}}=12.5 \mathrm{~mm}$ ). Only for $L_{\mathrm{O}}=50 \mathrm{~mm}$ this was not true, but in this case, due to the high loads involved, it was the adherends' failure that dictated $P_{\mathrm{m}}$. For this joint type, for short $L_{\mathrm{O}}$ the best results are obtained with the Araldite ${ }^{\circledR}$ AV138 and 2015. For intermediate $L_{\mathrm{O}}$, the Araldite ${ }^{\circledR} 2015$ clearly outperforms the other adhesives and the respective joints quickly reach the adherends' limiting strength. For bigger $L_{\mathrm{O}}$, the Araldite ${ }^{\circledR}$ AV138 becomes clearly inadequate, while the Sikaforce ${ }^{\circledR} 7752$ approached the Araldite ${ }^{\circledR}$ 2015 due to the limiting strength of the adherends.

Figure 12c presents the results for the stepped-lap joints bonded with the three adhesives studied in this work. The triangular CZM law resulted once again in a good $P_{\mathrm{m}}$ prediction for all $L_{\mathrm{O}}$. For the Araldite ${ }^{\circledR}$ AV138, the maximum deviation was $3.6 \%$, obtained for $L_{\mathrm{O}}=12.5 \mathrm{~mm}$. The reasons for this behaviour were previously documented. The predictive capabilities for the Araldite ${ }^{\circledR} 2015$ were also good, although for $L_{\mathrm{O}}=50 \mathrm{~mm}$ the $P_{\mathrm{m}}$ prediction was $2.0 \%$ above the experimental result (corresponding to the largest difference). The strength of the aluminium adherends was not attained, like in the DLJ, but the adherends suffered plastic deformation for $L_{\mathrm{O}}=50 \mathrm{~mm}$. For the Sikaforce ${ }^{\circledR} 7752$, the same discrepancy between numerical and experimental $P_{\mathrm{m}}$ values was found, with the numerical values falling short of the experiments. For this joint type, the deviation increases for higher $L_{\mathrm{O}}$. Thus, the maximum deviation was $13.9 \%$ for $L_{\mathrm{O}}=50 \mathrm{~mm}$. The best performing adhesive was the Araldite ${ }^{\circledR} 2015$, except for $L_{\mathrm{O}}=12.5 \mathrm{~mm}$, for which the Araldite ${ }^{\circledR}$ AV138 provided the highest $P_{\mathrm{m}}$. The Sikaforce ${ }^{\circledR} 7752$ only becomes competitive for large $L_{\mathrm{O}}$.

The $P_{\mathrm{m}}$ comparison for the scarf joints is presented in Fig. $12 \mathrm{~d}$ for the three tested adhesives. The Araldite ${ }^{\circledR}$ AV138 is clearly the best choice for this joint type, for all $L_{\mathrm{O}}$. The CZM predictions were very accurate, and they were always inside the experimental scatter, except for $L_{\mathrm{O}}=17.0 \mathrm{~mm}\left(\alpha=10^{\circ}\right)$ and $L_{\mathrm{O}}=5.2 \mathrm{~mm}\left(\alpha=30^{\circ}\right)$. The maximum error was found for the latter of these two, of $5.8 \%$. The good agreement extends to the Araldite ${ }^{\circledR}$ 2015. For this adhesive, the biggest discrepancy, of $8.0 \%$, was found for $L_{\mathrm{O}}=5.2 \mathrm{~mm}\left(\alpha=30^{\circ}\right)$. Moreover, only in this case was the numerical value outside of the experimental range (by approximately $130 \mathrm{~N}$ ). For the other $L_{\mathrm{O}}$, much smaller deviations were found. The numerical $P_{\mathrm{m}}$ values for the scarf joints bonded with the Sikaforce ${ }^{\circledR} 7752$ were typically below the experimental ones and outside the limits defined by the standard deviation. The maximum error was $12.7 \%$ for $L_{\mathrm{O}}=17.0 \mathrm{~mm}\left(\alpha=10^{\circ}\right)$. The reasons for this difference were already discussed. However, due to the more uniform stress distributions for the scarf joints (Figs. 9, 10), the under prediction is smaller, since the failure displacement of the CZM laws is not as preponderant as the cohesive strengths [32]. Also due to the typical shape of the stress distributions, the strong yet brittle Araldite ${ }^{\circledR}$ AV138 is clearly the best choice since, under these conditions, the ductility becomes almost irrelevant for $P_{\mathrm{m}}$. 


\title{
Conclusions
}

In this work, an experimental and numerical (CZM) comparison was made between several types of adhesive joints, and considering three adhesives. From the experimentally obtained results, it is possible to conclude that the performance of the joints is very influenced by the choice of the adhesive. For the Araldite ${ }^{\circledR}$ AV138 and large values of $L_{\mathrm{O}}$, the joint with the best performance was the scarf joint, because the this joint takes advantage of the adhesives' strength, even for brittle adhesives, due to the typically flat stress distributions. However, for shorter $L_{\mathrm{O}}$, due the area effect in the DLJ, these joints behave better. Higher $L_{\mathrm{O}}$ lead to large peak stresses and the area effect is cancelled because of the adhesive's brittleness. On the other hand, for the Araldite ${ }^{\circledR} 2015$, since this adhesive is more ductile, the DLJ performs best. Under these conditions, the joints take advantage of the higher bonded area, despite the peak stresses. The scarf joint approaches the DLJ for higher $L_{\mathrm{O}}$ because of taking advantage of the more uniform stress distributions and due the DLJ attaining the adherends' limit strength. The Sikaforce ${ }^{\circledR} 7752$ also performs best in the DLJ joint type. Moreover, for $L_{\mathrm{O}}=50 \mathrm{~mm}, P_{\mathrm{m}}$ is identical to the Araldite ${ }^{\circledR}$ 2015 due to the adherends' plastic deformation effect. The other joint types are much below the DLJ, with slight advantage for the scarf joint. However, the fabrication complications may not justify the advantage over the SLJ. The CZM simulations with triangular cohesive laws showed a good match to respective experiments, except for consistent $P_{\mathrm{m}}$ under predictions when using the Sikaforce ${ }^{\circledR} 7752$, because of the ductility of this adhesive, which is not correctly modelled with a triangular CZM. Nonetheless, rough predictions were achieved. The scarf joint showed slightly better strength predictions by CZM modelling. Actually, due to the improved stress distributions of this joint type, the cohesive strengths rule the failure process, instead of the failure displacements. The maximum errors obtained by joint type were as follows, always for the Sikaforce ${ }^{\circledR} 7752$ : $16.0 \%$ (SLJ), 15.6\% (DLJ), 13.9\% (stepped-lap joint) and 12.7\% (scarf joint). For the other adhesives, the correspondence was significantly better. Thus, it can be concluded that CZM is an accurate tool for the strength prediction of bonded joints, which enabled to define the best geometry for each adhesive type (and vice versa).

\begin{abstract}
Abbreviations
CZM: cohesive zone model; DCB: double-cantilever beam; DL: double-lap joint; E: Young's modulus; ENF: end-notched flexure; FEM: Finite Element Method; $G_{C}$ : fracture toughness; GFRP: glass-fibre reinforced polymer; $G_{I}:$ tensile toughness; $G_{\| C}$ : shear toughness; $G_{x y}$ : shear modulus; $L_{0}$ : overlap length; $L_{T}$ : total length of the joint between grips; $P_{m}$ : maximum load; $S L$ J: single-lap joint; $t_{\mathrm{A}}$ : adhesive thickness; $t_{\mathrm{A} 1}$ : vertical adhesive layers' thickness for the stepped-lap joints; TAST: thick adherend shear tests; $t_{m}^{0}$ cohesive strength in mixed-mode; $t_{p}$ : adherends' thickness; XFEM: extended finite element method; $\alpha$ : scarf angle; $\varepsilon$ : strain; $\varepsilon_{\mathrm{f}}$ failure strain; $\sigma:$ stress; $\sigma_{\mathrm{f}}$ : tensile strength; $\sigma_{\mathrm{y}}$ : through-thickness normal stresses; $\sigma_{\mathrm{y}}$ : yield stress; $\tau_{\text {avg: }}$ : average value of $\tau_{\mathrm{xy}}$ in the adhesive bond for respective value of $L_{0} ; \tau_{\mathrm{xy}}$ : shear stresses.
\end{abstract}

Authors' contributions

NGCB performed the experimental tests and respective data analysis, and he also performed the numerical analysis. RDSGC and RDFM developed the numerical technique and participated the paper writing. FJGS participated in the paper writing. All authors read and approved the final manuscript.

\section{Author details}

'Departamento de Engenharia Mecânica, Instituto Superior de Engenharia do Porto, Instituto Politécnico do Porto, Rua Dr. António Bernardino de Almeida, 431, 4200-072 Porto, Portugal. ${ }^{2}$ INEGI-Pólo FEUP, Rua Dr. Roberto Frias, s/n, 4200-465 Porto, Portugal.

Acknowledgements

The authors would like to thank Sika ${ }^{\circledR}$ Portugal for supplying the adhesive.

Competing interests

The authors declare that they have no competing interests. 
Availability of data and materials

The datasets used and/or analysed during the current study are available from the corresponding author on reasonable request.

\section{Funding}

No funding was received.

\section{Publisher's Note}

Springer Nature remains neutral with regard to jurisdictional claims in published maps and institutional affiliations.

Received: 26 October 2018 Accepted: 19 December 2018

Published online: 24 December 2018

\section{References}

1. da Silva LFM, Adams RD. Techniques to reduce the peel stresses in adhesive joints with composites. Int J Adhes Adhes. 2007;27(3):227-35. https://doi.org/10.1016/j.ijadhadh.2006.04.001.

2. Duong CN. A general approach to fracture analysis of tapered bonded joints and doublers. Eng Fract Mech. 2012;96:355-79. https://doi.org/10.1016/j.engfracmech.2012.08.013.

3. Petrie EM. Handbook of adhesives and sealants. New York: McGraw-Hill; 2000.

4. da Silva LFM, Öchsner A, Adams RD, editors. Handbook of adhesion technology. Heidelberg: Springer; 2011.

5. Volkersen O. Die nietkraftoerteilung in zubeanspruchten nietverbindungen konstanten loschonquerschnitten. Luftfahrtforschung. 1938;15:41-7.

6. Goland M, Reissner E. The stresses in cemented joints. J Appl Mech. 1944;66:A17-27.

7. Adams RD, Peppiatt NA. Stress analysis of adhesive-bonded lap joints. J Strain Anal Eng Des. 1974;9(3):185-96. https ://doi.org/10.1243/03093247V093185.

8. Ávila AF, Bueno PO. Stress analysis on a wavy-lap bonded joint for composites. Int J Adhes Adhes. 2004;24(5):407-14 https://doi.org/10.1016/j.ijadhadh.2003.12.001.

9. Adams RD, Harris JA. The influence of local geometry on the strength of adhesive joints. Int J Adhes Adhes. 1987;7(2):69-80. https://doi.org/10.1016/0143-7496(87)90092-3.

10. Williams ML. The stresses around a fault or crack in dissimilar media. Bull Seismol Soc Am. 1959;49(2):199-204.

11. Álvarez D, Blackman BRK, Guild FJ, Kinloch AJ. Mode I fracture in adhesively-bonded joints: a mesh-size independent modelling approach using cohesive elements. Eng Fract Mech. 2014;115:73-95. https://doi.org/10.1016/j.engfr acmech.2013.10.005.

12. Yang QD, Thouless MD. Mixed-mode fracture analyses of plastically-deforming adhesive joints. Int J Fract. 2001;110(2):175-87. https://doi.org/10.1023/A:1010869706996.

13. Mohammadi S. Extended finite element method for fracture analysis of structures. New Jersey: Blackwell Publishing 2008

14. Mubashar A, Ashcroft IA, Crocombe AD. Modelling damage and failure in adhesive joints using a combined XFEMcohesive element methodology. J Adhesion. 2014;90(8):682-97. https://doi.org/10.1080/00218464.2013.826580.

15. Silva TC, Nunes LCS. A new experimental approach for the estimation of bending moments in adhesively bonded single lap joints. Int J Adhes Adhes. 2014;54:13-20. https://doi.org/10.1016/j.ijadhadh.2014.04.006.

16. Sayman O. Elasto-plastic stress analysis in an adhesively bonded single-lap joint. Compos Part B. 2012;43(2):204-9. https://doi.org/10.1016/j.compositesb.2011.08.006.

17. Nunes SLS, Campilho RDSG, da Silva FJG, de Sousa CCRG, Fernandes TAB, Banea MD, da Silva LFM. Comparative failure assessment of single and double lap joints with varying adhesive systems. J Adhes. 2016;92(7-9):610-34. https ://doi.org/10.1080/00218464.2015.1103227.

18. Gacoin A, Lestriez P, Assih J, Objois A, Delmas Y. Comparison between experimental and numerical study of the adhesively bonded scarf joint and double scarf joint: influence of internal singularity created by geometry of the double scarf joint on the damage evolution. Int J Adhes Adhes. 2009;29(5):572-9. https://doi.org/10.1016/j.ijadh adh.2009.01.006.

19. Arciszewska-Kędzior A, Kunecký J, Hasníková H, Sebera V. Lapped scarf joint with inclined faces and wooden dowels: experimental and numerical analysis. Eng Struct. 2015;94:1-8. https://doi.org/10.1016/j.engstruct.2015.03.036.

20. Papanicolaou GC, Charitidis PJ, Mouzakis DE, Jiga G. Experimental and numerical investigation of unbalanced boron/epoxy-aluminum single lap joints subjected to a corrosive environment. J Compos Mater. 2015;50(2):145-57. https://doi.org/10.1177/0021998315571773.

21. Lee HK, Pyo SH, Kim BR. On joint strengths, peel stresses and failure modes in adhesively bonded double-strap and supported single-lap GFRP joints. Compos Struct. 2009;87(1):44-54. https://doi.org/10.1016/j.compstruct .2007.12.005.

22. Liao L, Huang C, Sawa T. Effect of adhesive thickness, adhesive type and scarf angle on the mechanical properties of scarf adhesive joints. Int J Solids Struct. 2013;50(25):4333-40. https://doi.org/10.1016/j.ijsolstr.2013.09.005.

23. Moreira RDF, Campilho RDSG. Strength improvement of adhesively-bonded scarf repairs in aluminium structures with external reinforcements. Eng Struct. 2015;101:99-110. https://doi.org/10.1016/j.engstruct.2015.07.001.

24. Akpinar S. The strength of the adhesively bonded step-lap joints for different step numbers. Compos Part B. 2014:67:170-8. https://doi.org/10.1016/j.compositesb.2014.06.023.

25. Ichikawa K, Shin Y, Sawa T. A three-dimensional finite-element stress analysis and strength evaluation of stepped-lap adhesive joints subjected to static tensile loadings. Int J Adhes Adhes. 2008;28(8):464-70. https://doi.org/10.1016/j. ijadhadh.2008.04.011 
26. ASTM-E8 M-04. Standard test methods for tension testing of metallic materials [Metric]. West Conshohocken: ASTM International; 2004

27. Campilho RDSG, Banea MD, Neto JABP, da Silva LFM. Modelling adhesive joints with cohesive zone models: effect of the cohesive law shape of the adhesive layer. Int J Adhes Adhes. 2013;44:48-56. https://doi.org/10.1016/j.ijadh adh.2013.02.006.

28. Campilho RDSG, Banea MD, Pinto AMG, da Silva LFM, de Jesus AMP. Strength prediction of single- and doublelap joints by standard and extended finite element modelling. Int J Adhes Adhes. 2011;31(5):363-72. https://doi. org/10.1016/j.jjadhadh.2010.09.008.

29. Faneco T, Campilho R, Silva F, Lopes R. Strength and fracture characterization of a novel polyurethane adhesive for the automotive industry. J Test Eval. 2017;45(2):398-407. https://doi.org/10.1520/JTE20150335.

30. Carvalho UTF, Campilho RDSG. Validation of pure tensile and shear cohesive laws obtained by the direct method with single-lap joints. Int J Adhes Adhes. 2017;77(Supplement C):41-50. https://doi.org/10.1016/j.ijadh adh.2017.04.002.

31. Alfano G. On the influence of the shape of the interface law on the application of cohesive-zone models. Compos Sci Technol. 2006;66(6):723-30. https://doi.org/10.1016/j.compscitech.2004.12.024.

32. Campilho RDSG, Banea MD, Neto JABP, da Silva LFM. Modelling of single-lap joints using cohesive zone models: effect of the cohesive parameters on the output of the simulations. J Adhes. 2012;88(4-6):513-33. https://doi. org/10.1080/00218464.2012.660834

33. Ribeiro ML, Tita V. Bonded joints design aided by computational tool. J Aerosp Technol Manag. 2012;4:275-88.

34. Zhao B, Lu Z-H, Lu Y-N. Two-dimensional analytical solution of elastic stresses for balanced single-lap joints-Variational method. Int J Adhes Adhes. 2014;49:115-26. https://doi.org/10.1016/j.jiadhadh.2013.12.026.

35. Bendemra H, Compston P, Crothers PJ. Optimisation study of tapered scarf and stepped-lap joints in composite repair patches. Compos Struct. 2015;130:1-8. https://doi.org/10.1016/j.compstruct.2015.04.016.

36. Vallée T, Correia JR, Keller T. Probabilistic strength prediction for double lap joints composed of pultruded GFRP profiles part l: experimental and numerical investigations. Compos Sci Technol. 2006;66(13):1903-14. https://doi. org/10.1016/j.compscitech.2006.04.007.

37. de Sousa CCRG, Campilho RDSG, Marques EAS, Costa M, da Silva LFM. Overview of different strength prediction techniques for single-lap bonded joints. J Mater Des Appl L. 2017;231:210-23. https://doi.org/10.1177/1464420716 675746.

38. Baker AA, Chester RJ, Hugo GR, Radtke TC. Scarf repairs to highly strained graphite/epoxy structure. Int J Adhes Adhes. 1999;19(2-3):161-71. https://doi.org/10.1016/S0143-7496(98)00031-1.

39. Goglio L, Rossetto M, Dragoni E. Design of adhesive joints based on peak elastic stresses. Int J Adhes Adhes. 2008;28(8):427-35. https://doi.org/10.1016/j.ijadhadh.2008.04.001.

40. Campilho RDSG, de Moura MFSF, Domingues JJMS. Stress and failure analyses of scarf repaired CFRP laminates using a cohesive damage model. J Adhes Sci Technol. 2007;21(9):855-70. https://doi.org/10.1163/156856107781061 477.

41. Feraren P, Jensen HM. Cohesive zone modelling of interface fracture near flaws in adhesive joints. Eng Fract Mech. 2004;71(15):2125-42. https://doi.org/10.1016/j.engfracmech.2003.12.003.

\section{Submit your manuscript to a SpringerOpen ${ }^{\circ}$ journal and benefit from:}

- Convenient online submission

- Rigorous peer review

- Open access: articles freely available online

- High visibility within the field

- Retaining the copyright to your article

Submit your next manuscript at $\mathbf{s p r i n g e r o p e n . c o m ~}$ 